\title{
Chica Brincuda, "a última a ficar nestas terras de escravos": mulheres negras no Litoral Negro do Rio Grande do Sul
}

Chica Brincuda, "the last to stay in this slavery land": Black women in the black coast of Rio Grande do Sul

\section{Claudia Daiane Garcia Molet}

Resumo: Neste artigo, tenho o objetivo de analisar as experiências de mulheres negras no Litoral Negro do Rio Grande do Sul, visando destacar os arranjos familiares marcados pela matrilinearidade, as memórias da escravidão e as experiências no pós-abolição. Aciono as memórias e histórias de Chica Brincuda, rememorada na comunidade remanescente quilombola do Limoeiro como "a última a ficar nestas terras de escravos". Para isso, aciono as memórias dos quilombolas e outros documentos escritos, como testamentos, alforrias e registros de batismos.

Palavras-chave: mulheres negras; Litoral Negro; escravidão; liberdade.

Abstract: In this article I have the goal to consider the black women's experiences, in the black coast of Rio Grande do Sul, to highlight the family structure marked by the motherly heritage, slavery memories and experiences after abolition. I go back to memories and stories of the renowned Chica Brincuda in the Limoeiro Quilombola remnant community, as "the last to stay in this slavery land". For this I go back to the memories of Quilombolas and other documents, writings as testaments, emancipations and baptism certificates.

Keywords: black women; black coast; slavery; freedom.

Doutora em História (UFRGS), com pesquisa financiada pela CAPES. Assistente em Administração na UFPel. E-mail: claudiamolet@yahoo.com.br. ORCID: https://orcid.org/0000-0002-9426-5231. 


\section{Mulheres negras: raça, classe social e gênero}

Angela Davis, ${ }^{1}$ ao analisar as experiências das mulheres negras estadunidenses, pontua que "o ponto de partida de qualquer exploração da vida das mulheres negras na escravidão seria uma avaliação de seu papel como trabalhadoras". As mulheres negras, assim como os homens negros, eram vistas como unidades de trabalho lucrativas, e desse modo, para os proprietários de escravizados, elas de fato poderiam ser desprovidas de gênero. Para a autora, a ideologia da feminilidade do século XIX, que destacava o papel das mulheres como mães protetoras, parceiras e donas de casa amáveis para seus maridos, deixava a mulher negra como um produto anômalo, ainda que elas desfrutassem "alguns benefícios duvidosos" da ideologia da feminilidade, já que a típica escravizada seria aquela que desempenhava as atividades na lida doméstica. Porém, assim como os escravizados, a maioria das escravizadas labutava na lavoura. E, na lavoura, o trabalho começava do amanhecer ao pôr do sol sob a ameaça do açoite, independente do gênero da mão de obra. Porém, as mulheres sofriam outras formas de violência relacionadas ao gênero, pois eram vítimas de abusos sexuais e de outros maus-tratos bárbaros específicos a sua condição de gênero. As mulheres negras escravizadas eram duplamente tratadas por seus senhores, tanto poderiam ser desprovidas de gênero e, assim, exploradas igualmente aos homens, quanto reduzidas a sua condição de gênero, e assim poderiam ser abusadas, punidas e reprimidas. Desse modo, é pertinente que um olhar atento às suas experiências seja realizado para se compreender a complexidade de ser mulher negra.

Perrot $^{2}$ afirma que foi a partir do século XIX, na França, que ocorreu a divisão das tarefas e a segregação dos espaços, determinando as atividades da vida para homens e mulheres, designando-se para estas a maternidade e a casa. Além disso, a participação feminina nas ocupações assalariadas foi temporária, pois ocorria quando havia a necessidade de uma maior renda para a família. Essas mulheres foram remuneradas com baixos salários e realizavam atividades não qualificadas. Importante mencionar que esse ideário burguês, em que a divisão das tarefas era de acordo com o sexo, não foi possível de ser realizado, no caso das mulheres pobres que necessitavam trabalhar em várias ocupações para manter sua família e seu lar. No caso do Brasil, o sistema escravista existiu até praticamente o fim do século XIX, e aquelas mulheres escravizadas, libertas, pardas e pretas sofreram ainda maior

DAVIS, Angela. Mulheres, raça e classe. São Paulo: Boitempo Editorial, 2016.

PERROT, Michelle. Os excluídos da história: operários, mulheres e prisioneiros. Rio de Janeiro: Paz e Terra, 1988. 
preconceito. O silêncio para elas foi maior. Entretanto, esse silêncio na história das mulheres foi estabelecido pelos homens ou por membros da elite, e entre estes, possivelmente, as mulheres brancas. Contudo, se a elite fez questão de não dar voz a essas mulheres, elas mesmas se fizeram ser ouvidas. E no caso das mulheres litorâneas do Rio Grande do Sul, algumas de suas histórias são rememoradas por seus ancestrais quilombolas na atualidade.

Entre as principais atividades exercidas pelas mulheres pobres, no período compreendido entre 1890 e 1920, no Rio de Janeiro, segundo Soihet, ${ }^{3}$ estavam as de lavadeira, rendeira, costureira, doceira, engomadeira; todos esses trabalhos eram mal remunerados. Outras trabalhavam no pequeno comércio e ainda como operárias nas indústrias. Muitas das mulheres pesquisadas pela autora eram prostitutas. Aquelas que residiam nas áreas rurais próximas da cidade trabalhavam na lavoura. Segundo Soihet, no caso das mulheres, as atividades que desempenhavam faziam com que as mesmas tivessem comportamentos específicos a elas, pois refletiam na maneira de pensar e de viver. Eram trabalhadoras menos inibidas do que as demais mulheres de outras classes sociais, tinham um linguajar "mais solto", maior liberdade de locomoção e iniciativa de decisões. Todavia, para Soihet, houve um duplo preconceito para com as mulheres: aquele de gênero e o de classe. $O$ cotidiano das trabalhadoras fez com que tivessem comportamentos diferenciados das senhoras da sociedade. Soma-se a isso a questão de classe, pois sendo pertencentes à classe pobre, nela permaneceram, pois para elas sobravam as ocupações mal remuneradas, que apenas serviram para que pudessem suprir as necessidades mínimas de sobrevivência. O silêncio imposto pelas autoridades não foi obedecido por essas trabalhadoras, seja no dia a dia do trabalho, seja nos momentos de lazer e de solidariedade. Apesar de a autora analisar o período pós-abolição, vale ressaltar que as mulheres tiveram essas necessidades desde o sistema escravista, pois houve uma variedade de ocupações desempenhadas por elas, visto que necessitavam sair às ruas em busca de seus sustentos.

Miriam Moreira Leite ${ }^{4}$, ao verificar a condição feminina, no Rio de Janeiro, durante o século XIX, acrescenta que o ideal da mulher reclusa fez com que aquelas que circularam pelas ruas fossem estigmatizadas. Além disso, para as escravas, acentuou-se mais o preconceito, pois além de sua condição de cativa, muitas circularam pelas ruas e tiveram contato com homens. Desse modo, o trabalho manual e a rua foram considerados como coisas de escravizadas e/ou prostitutas.

SOIHET, Rachel. Condição feminina e formas de violência: mulheres pobres e ordem urbana (1890-1920). Rio de Janeiro: Forense Universitária, 1989.

4 LEITE, Miriam Moreira. A condição feminina no Rio de Janeiro, século XIX. São Paulo: Hucitec, 1993. 
Margareth Rago ${ }^{5}$ informa que a estratégia da correção da moral feminina foi uma tentativa de regrar o cotidiano das mulheres, especialmente as trabalhadoras que saíram para as ruas, tendo contato principalmente com as classes populares e com seus hábitos indisciplinados.

$E$ as mulheres negras que desempenhavam suas atividades nas zonas rurais? No Litoral Negro, algumas mulheres escravizadas conquistaram liberdade e bens de seus antigos senhores e senhoras, ainda no século XIX. Infelizmente, não constam nos documentos analisados as ocupações daquelas trabalhadoras, mas se pensarmos na historiografia, sabe-se que desempenhavam, principalmente, atividades domésticas no interior das casas-grandes. Possivelmente, a proximidade com a casa-grande tenha auxiliado na conquista de um legado diferenciado quando comparado aos herdeiros homens, seja ganhando um escravizado, determinados bens, ou ainda pelo zelo ao filho menor.

Graham, ${ }^{6}$ ao estudar o trabalho feminino no Rio de Janeiro, especialmente aquele exercido pelas criadas, lembra que a vida doméstica era compartilhada por criadas e senhores. As criadas presenciavam cotidianamente os hábitos e os acontecimentos privados da vida familiar senhorial. Do mesmo modo, as criadas não conseguiam ocultar dos senhores suas preocupações e comportamentos. Assim, ser uma criada era viver próxima de um senhor ou amo. Havia uma relação entre ambos os lados: as criadas deviam trabalhar e obedecer e, em troca, os senhores Ihes davam proteção. Empregar uma criada era colocar uma pessoa estranha na intimidade de sua família, porém os senhores precisavam dessa mão de obra. Entretanto, as tratavam com a mesma suspeição que tinham para com os pobres e com os negros em geral. Dentre os criados de casa, as mulheres representavam o maior risco, pois geralmente suas atividades eram realizadas no âmbito pessoal, como no caso das amas de leite, a quem os senhores confiavam a vida e o bem-estar de seus filhos, porém tinham medo de que os mesmos fossem infectados com "doenças assustadoras". Desse modo, a figura da ama de leite representava o dilema que viviam os senhores em relação às criadas.

As mulheres litorâneas trabalhavam na casa de seus senhores e senhoras, cuidando da alimentação, da limpeza, das roupas. Para além destas ocupações, é de se pensar que elas também cuidavam de suas plantações, pois é comum nas narrativas, dos atuais quilombolas, casos em que as mulheres cuidam de hortas. Entretanto, para além das hortas e das lides domésticas, as mulheres

5 RAGO, Margareth. Do cabaré ao lar: a utopia da cidade disciplinar, Brasil (1890-1930). Rio de Janeiro: Paz e Terra, 1985.

6 GRAHAM, Sandra Lauderdale. Proteção e obediência: criadas e seus patrões no Rio de Janeiro, 1860-1910. Tradução de Viviana Bosi. São Paulo: Companhia das Letras, 1992. 
negras também atuavam em redes de apoio, como parteiras e benzedeiras. Numa região com grande dificuldade de locomoção e de difícil acesso à medicina oficial, as parteiras e as benzedeiras foram de suma importância para a saúde dos camponeses negros.

\section{O Litoral Negro do Rio Grande do Sul}

Entendo o "Litoral Negro" do Rio Grande do Sul como um espaço geográfico marcado pela presença de oito comunidades remanescentes quilombolas, ${ }^{7}$ situado na estreita faixa de terras entre a laguna dos Patos e o Oceano Atlântico, abrangendo os atuais munícipios de São José do Norte, Tavares, Mostardas e Palmares do Sul; mas, também, como um conceito que possibilita entender as diversas interligações qualificadas pelos laços de amizades, parentescos e compartilhamento de práticas culturais, desde pelo menos o século XIX, muitas delas surgidas no cativeiro. Flávio Gomes utiliza o conceito de "campo negro" em outro contexto, pois aborda o século XIX, a partir de uma perspectiva de quilombo como um núcleo formado com as fugas de escravos, embora não dialogue com a definição clássica de quilombo marcado pelo isolacionismo, ao contrário, defende que, durante o século XIX, havia uma "hidra ${ }^{8}$ no recôncavo da Guanabara", quase que indestrutível. Segundo o autor, as comunidades de escravos fugitivos começaram a surgir depois de 1800, permanecendo e atormentando os moradores e as autoridades até o final do século XIX; assim, "por quase um século, os quilombos sobreviveram e se fortaleceram em Iguaçu, a despeito dos esforços para destruí-los. Inúmeras expedições atacaram os mocambos, destruíram ranchos e roças e capturaram alguns habitantes". Porém, os quilombos ressurgiam semelhantes a uma hidra.

Gomes afirma que a geografia da localidade foi importante para o desenvolvimento das comunidades de escravos fugidos, pois eram formadas por uma extensa planície com riachos e pântanos, possibilitando, desse modo, "refúgios seguros". Além disso, para o autor, a escolha da localização das comunidades foi fundamental tanto para a sobrevivência quanto para a autonomia, pois estava

No Brasil, a temática quilombola tornou-se frequente no meio acadêmico, político, jurídico e social com o artigo 68 da Constituição de 1988 e posteriormente com o Decreto n. ${ }^{\circ} 4.887$, de 20 de novembro de 2003. Embora os quilombos estejam presentes no Brasil desde o período colonial, foi apenas no decorrer do século XX que os estudos começaram a ser realizados numa perspectiva histórica.

8 O termo hidra tem sua origem na Grécia e dava nome a um dragão que tinha inúmeras cabeças e que era invencível. Quando o ministro da Justiça, Gama Cerqueira, foi relatar sobre as comunidades negras da região da Guanabara, em 1878, mencionou que eram como uma hidra. GOMES, Flávio dos Santos. História dos quilombolas: mocambos e comunidades de senzalas no Rio de Janeiro, século XIX. São Paulo: Companhia das Letras, 2006. 
relacionada com a possibilidade de manter práticas econômicas. ${ }^{9}$ Desse modo, segundo o autor: “o 'campo negro' seria uma complexa rede social, constituída por lutas e solidariedades entre quilombolas, mas também entre cativos, libertos e outros trabalhadores das localidades próximas". O "campo negro" de Gomes, formado por diferentes agentes sociais, pode ser utilizado, ressalvadas as peculiaridades e apontando as recorrências, para se pensar as comunidades remanescentes de quilombolas que surgiram no século XIX, marcadas não pelo isolacionismo, mas sim por interligações, entre elas, com escravos de senzalas vizinhas, outros núcleos de libertos e ainda vizinhos. O Litoral Negro dialoga, portanto com o "campo negro" de Gomes na medida em que ele surge no século XIX, a partir de relações sociais entre escravos, libertos e livres.

Algumas pesquisas que investigam comunidades remanescentes de quilombos assinalam a existência de uma territorialidade negra que se estende para além das linhas físicas do quilombo. Os estudos de Dos Anjos e Silva que resultaram no relatório socio-histórico e antropológico das comunidades quilombolas de São Miguel e Martiminiano, localizadas em Restinga Seca, no Rio Grande do Sul, demonstram interligações entre esses mocambos. A memória coletiva traz inúmeros laços de reciprocidade que são fundados, principalmente, pelo reconhecimento de pertença a um mesmo grupo étnico, pelas redes de sociabilidade e pelas alianças matrimoniais que fortalecem as ligações étnico-culturais; além disso, a fundação desses quilombos aponta para laços de parentesco das primeiras famílias negras. ${ }^{10}$

Costa, em sua dissertação de mestrado em Antropologia Social, investiga três comunidades situadas na divisa dos municípios de Gravataí e Viamão, no Rio Grande do Sul: Anastácia, Manoel Barbosa e Ferreira-Fialho. O autor defende a existência de um território negro que se estende para além das fronteiras de cada um desses quilombos, marcado por afetividades e por representações, mesmo que haja uma descontinuidade espacial e física. A "abrangência geográfica e genealógica" que percebeu a partir do contato com os quilombolas e com o conhecimento das trajetórias fez com que o autor buscasse estudar a presença negra na região, considerando outros locais fora da fronteira espacial dos quilombos. ${ }^{11}$

O historiador Rodrigo de Azevedo Weimer, em sua tese de doutorado em História, faz importantes reflexões sobre o litoral do Rio Grande do Sul, em

\footnotetext{
Ibidem.

10 DOSANJOS, José Carlos Gomes; SILVA, Sergio Baptista. São Miguel e Rincão dos Martiminianos: ancestralidade negra e direitos territoriais. Porto Alegre: Editora da UFGRS, 2004.

11 COSTA, Luciano Souza. Anastácia, Manoel Barbosa e Ferreira-Fialho, famílias e territórios negros: tradição e dinâmica territorial em Gravataí e Viamão. 2007. Dissertação (Mestrado em Antropologia Social) - Universidade Federal do Rio Grande do Sul, Porto Alegre, 2007.
} 
especial a região de Osório, a partir de um recorte geracional onde analisa a trajetória da "gente" da Felisberta, dividida em quatro gerações: escravos, camponeses, migrantes e quilombolas. Weimer aponta que o litoral norte sofreu uma relativa marginalidade após a decadência do tráfico negreiro. Essa situação teria ensejado a formação de um campesinato negro a partir do acesso à terra, tanto costumeiro quanto legalizado. Além disso, argumenta que atualmente há laços de parentescos, práticas culturais e projetos políticos entre diversas localidades que marcam a tessitura da comunidade negra de Morro Alto: Morro Alto, Aguapés, Barranceira, Faxinal do Morro Alto, Ramalhete, Ribeirão do Morro Alto, Borba, Espraiado e Prainha. ${ }^{12}$

No Litoral Negro, marcado por intensas redes de parentescos e solidariedades, ${ }^{13}$ Chica Brincuda deixou suas memórias e histórias rememoradas pelos remanescentes quilombolas do Limoeiro, situado no atual município de Palmares do Sul. Desde a primeira vez em que visitei a comunidade do Limoeiro, em 2008, escutei as memórias quilombolas sobre Francisca Joana Gomes, conhecida como Chica Brincuda, rememorada pela comunidade como a última escravizada a andar pelas terras de Palmares, na região do Ipê. Chica, possivelmente, foi uma das herdeiras das terras dos Gomes. Segundo as memórias dos entrevistados, a escravizada teria vindo com seu proprietário de Santo Antônio da Patrulha para Palmares.

\section{Chica Brincuda: memórias de uma mulher negra no Limoeiro}

A Fazenda do Ipê era uma propriedade do capitão Vicente José Gomes e de sua mulher, Gertrudes Eufrázia Lopes; ambos vieram de Santo Antônio da Patrulha. Vicente comprou terras dos herdeiros Azevedo e Souza ${ }^{14}$ e foi morar na região do atual município de Palmares do Sul; juntamente com ele, trouxe seus escravizados. Nos anos de 1870 a 1871, o casal Vicente e Eufrázia concedeu carta de alforria a 16 escravos.

12 WEIMER, Rodrigo de Azevedo. A gente da Felisberta. Consciência histórica, história e memória de uma família negra no litoral sul-rio-grandense no pós-emancipação. (c.1847 ao tempo presente). 2013. Tese (Doutorado em História) - Universidade Federal Fluminense, Niterói, 2013.

13 MOLET, Claudia Daiane Garcia. Parentescos, solidariedades e práticas culturais: estratégias de manutenção de um campesinato negro no Litoral Negro do Rio Grande do Sul (do século XIX ao tempo presente). 2018. Tese (Doutorado em História) - Universidade Federal do Rio Grande do Sul, Porto Alegre, 2018.

14 Antônio de Azevedo de Souza casou-se com Mônica Pereira de Souza, então viúva de Manoel Jorge da Silva, proprietário das antigas sesmarias da região. 
Quadro 1: Alforrias dos escravizados de Vicente José Gomes e Gertrudes Eufrázia Lopes.

\begin{tabular}{|c|c|}
\hline Alforriado & Idade \\
\hline Belizária & 70 \\
\hline Narcisa & 53 \\
\hline Tomázia & 43 \\
\hline Isalina & 43 \\
\hline Catarina & 40 \\
\hline Angélica & 36 \\
\hline Laurinda & 32 \\
\hline Florinda & 29 \\
\hline Francisco & 23 \\
\hline Albino & 25 \\
\hline Maria & 29 \\
\hline Firmino & 20 \\
\hline Ana & 18 \\
\hline Elisa & 10 \\
\hline Manoel & 2 \\
\hline "sem nome" & 1 \\
\hline
\end{tabular}

Fonte: Rio Grande do Sul, Secretaria da Administração e dos Recursos Humanos. Documentos da escravidão catálogo seletivo de cartas de liberdade. Acervo dos tabelionatos do interior do Rio Grande do Sul. Porto Alegre: CORAG, 2006. p. 932-933.

O quadro 1 foi realizado a partir de três registros de alforrias. A liberdade de Belizária, que tinha 70 anos de idade, foi concedida por Vicente José Gomes "pelos bons serviços que me tem prestado e à minha mulher, pela sua fidelidade", registrada em 1870. Já o segundo registro é de 1871 e nele constam 14 escravos. As cartas de alforria foram concedidas em razão de serem "crias de casa, filhos e netos das ditas minhas escravas Narcisa, Isalina e de outras". Aqui, nota-se a existência de uma família negra extensa, composta por, pelo menos, 14 escravizados que vivenciaram as mesmas experiências no interior da senzala do capitão e de sua mulher. O último registro é de Francisco, filho de Isalina, também escrava de Vicente. A carta foi dada em decorrência de que "há muitos anos, dei ao meu sobrinho Jerônimo José Lopes, para dele servir-se como seu verdadeiro escravo, durante sua vida, e por morte de meu dito sobrinho Jerônimo, ficará o mesmo mulato Francisco liberto". 16 escravos foram alforriados pelo casal Vicente José Gomes e Gertrudes Eufrázia Lopes, nos anos de 1870 e 1871 , sendo que havia 11 mulheres, cinco homens e um que não é possível saber o sexo, pois não havia sido batizado até aquele momento e logo não foi registrado seu nome.

Em 1873, Gertrudes Eufrásia Lopes declarou em seu testamento que tinha 82 anos de idade e era casada com Vicente José Gomes e que não possuíam filhos. $O$ 
testamento foi realizado no distrito de Palmar, no lugar denominado Ipê. Quanto aos bens que Gertrudes deixou para os escravos alforriados:

Deixo aos meus escravos e escravas que eu e meu marido demos
liberdade os bens seguintes: a casa de moradia no Ipê, as casas
de carretas juntas a mesma casa, e todas as mais benfeitorias no
mesmo lugar, o quinhão de campo comprado a Domingos José de
Araújo Basto, na sesmaria da Charqueada, a casa de atafona e
todos os seus pertences, duas partes de campo compradas, uma
a Candido Rodrigues Pereira, e outra a Luiz Inácio Pereira Abreu,
pertencentes à sesmaria do Frei Bastião; uma carreta em bom
estado; seis juntas de bois mansos, quarenta éguas xucras, dois
cavalos mansos, duzentas ovelhas; duas caixas grandes, duas
mais pequenas, um armário grande, um oratório com imagens,
cujos bens os escravos que ficarem libertos, por minha morte
e de meu marido, serão deles senhores, com a condição de
não venderem bens de raiz nenhuma e nem alienar por forma
alguma e só poderão deles tomarem conta depois de minha
morte e de meu marido Vicente José Gomes. Declaro que deixo
duzentas reses de criar para minhas escravas que eu e meu marido
temos libertado a saber divididas pelas cinco que aqui declaro seus
nomes: Narciza, Zelinda, Catarina, Tomázia e Juliana. ${ }^{15}$

Pelo testamento de Gertrudes, percebe-se que ela deixou para os escravos terras na sesmaria de Charqueada e na sesmaria de Frei Bastião. Além disso, os libertos conquistaram a casa de morada no Ipê, uma casa de atafona, uma carreta, uma junta de bois, além de outros pequenos bens. Para Narciza, Zelinda, Catarina, Tomázia e Juliana deixou 200 reses de criar. Desse modo, Gertrudes, na hora de dividir os bens entre os escravos, teve um cuidado maior para determinar a herança para as mulheres. Esse "cuidado" pode ser pensado a partir da aproximação das escravas com o interior das residências das senhoras. Não pretendo amenizar a experiência da escravidão para as mulheres e excluir dela a violência inerente a esse sistema, mas afirmar que os escravos, e principalmente as mulheres, poderiam saber as regras do jogo e perceber que era possível ter maiores benefícios a partir de algumas articulações. Vicente possivelmente viaja constantemente e por isso trabalhar no interior da residência poderia trazer às escravizadas uma proximidade maior com as mulheres, que não tinham filhos e que poderiam passar longos períodos sozinhas.

Aconquista desses imóveis negros pode ter sido garantida a partir da existência de arranjos familiares, desde o século XVIII, quando os sujeitos eram escravizados. Após a emancipação, as famílias ajudaram na manutenção dos terrenos. Slenes ${ }^{16}$ afirma que a historiografia clássica, ao abordar a família escrava, tratou de indicar a

15 Cartório de Órfãos e Provedoria de Santo Antônio da Patrulha, caixa n. 2, auto n. 93, testamento de Gertrudes Eufrázia Lopes, 1873, grifo nosso. Arquivo Público do Estado do Rio Grande do Sul (APERS).

16 SLENES, Robert W. Na senzala uma flor. Esperanças e recordações na formação da família escrava: Brasil Sudeste, século XIX. Campinas: Editora da Unicamp, 2011. 
promiscuidade sexual, as uniões conjugais instáveis, os filhos que cresciam sem a presença paterna, ou ainda, que mal sabiam quem era a mãe e os irmãos. Porém, a partir da década de 1970, surgiu um novo paradigma ancorado principalmente em novas fontes demográficas e com foco no Sudeste do país, ao longo do século XIX, que contesta "diretamente a antiga visão da vida sexual e familiar do escravo como pouco mais do que uma desordem cultural, (ou nas palavras de Bastide) uma 'vasta promiscuidade primitiva'."17 As pesquisas têm indicado, segundo o autor, para as áreas de plantation do Sudeste, a existência de laços de parentescos "simples", marcados pelos vínculos entre cônjuges e entre pai/mãe e filhos e também de famílias extensas que incluíam os indivíduos não aparentados. Além disso, tais pesquisas apontam que a formação de famílias era um interesse dos escravizados como parte de uma estratégia de sobrevivência no interior das senzalas.

Para Slenes, a família escrava era um projeto de vida, ou seja, não configurava uma "brecha camponesa", mas sim um campo de batalha onde brigavam senhores e escravos. Ao identificar as vantagens do casamento para os escravizados, o autor pontua que o parceiro seria uma mão amiga quando era necessário enfrentar privações e punições. Entre outros benefícios do casamento, o autor destaca a conquista de ganhar maior controle sobre o espaço da moradia; controle do preparo da comida; possibilidade de criar animais, caçar e plantar alimentos. Desse modo, haveria "mais controle sobre sua economia doméstica". Esse projeto de vida, marcado por laços de parentescos, mas não exclusivamente, possibilitava uma mudança na história do escravo, porém, conforme pontua o autor, a família era um "campo de batalha", local onde senhores e escravos lutavam. Afinal, a qualquer momento o escravo poderia ter sua família vendida para outros senhores. Por isso, se de um lado poderia ser uma tentativa de o senhor manter o escravo na fazenda ao não proibir a formação de família, mas para o escravo poderia ser a possibilidade de controlar sua "economia doméstica".

Retornando a Chica Brincuda, nas entrevistas, quando os quilombolas eram interrogados sobre essa ancestral, o nome de Anastácia Gomes e de Juliana Anastácia Gomes emergiram nas memórias, porém não conseguimos detectar quais parentescos ligavam essas duas mulheres a Chica. Possivelmente, elas mantinham laços de solidariedade ou de parentescos amalgamados ainda na época do cativeiro. Pelos registros de batismos, é possível identificar que Anastácia era mãe de Juliana que, por sua vez, foi mãe de, pelo menos, seis filhos: Maria Carolina, Gaspar, Vicente, José, Alzemiro e Juca Grande, conforme gráfico genealógico a

$17 \quad$ Ibidem, p. 53. 
seguir. Cabe salientar que o nome de Juliana aparece no testamento de Gertrudes Eufrázia Lopes como uma escravizada prestes a adquirir a liberdade e bens assim que o marido de Gertrudes, Vicente José Gomes, viesse a falecer.

Gráfico genealógico 1: Família de Anastácia Gomes e Juliana Anastácia Gomes.

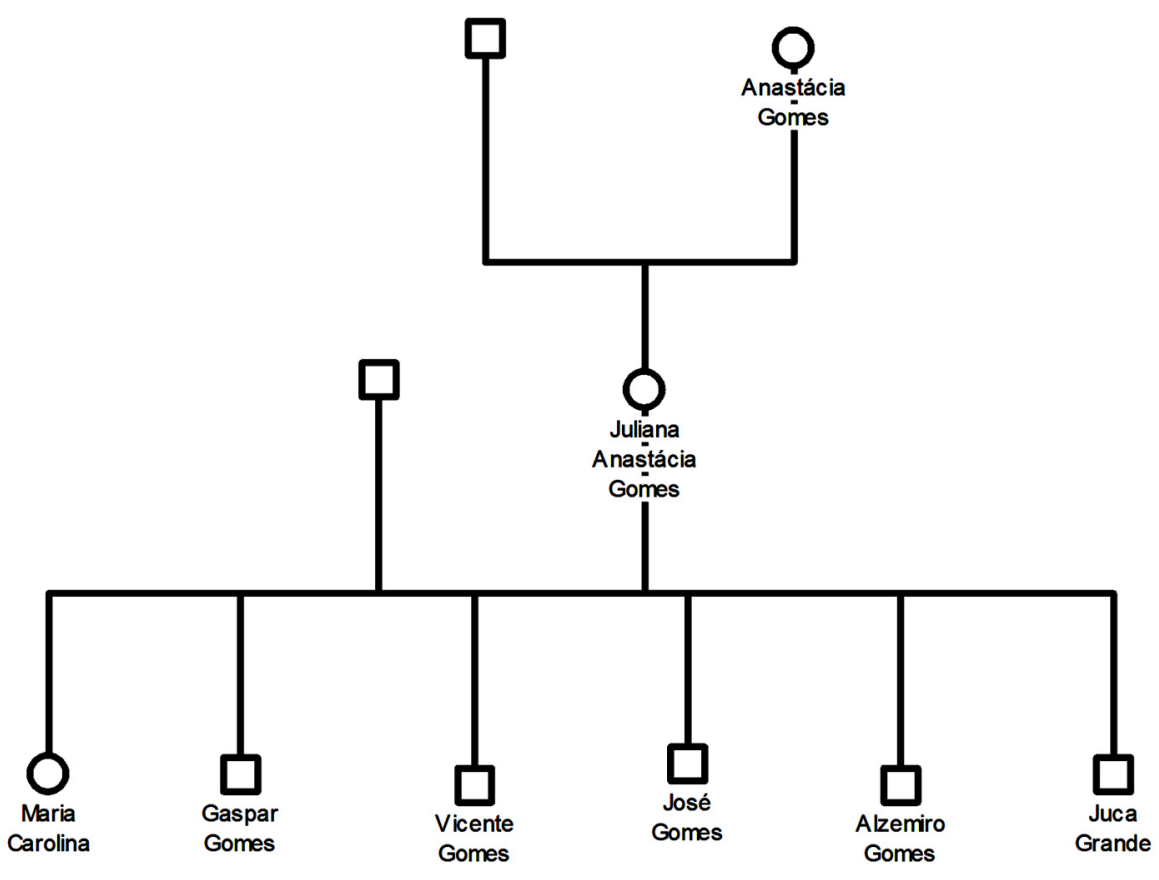

Foi possível encontrar o nome da mãe de Juliana Anastácia Gomes, mas, provavelmente, assim como a filha, Anastácia Gomes pode ter sido escravizada em alguma fazenda litorânea. Juliana, após a liberdade, teve cinco filhos. Encontramos o batizado de três deles, todos registrados em Nossa Senhora da Conceição do Arroio. ${ }^{18}$ Desse modo, percebe-se a permanência da família de Juliana na região da antiga Fazenda do Ipê, após a conquista da liberdade, provavelmente na década de 1870 e após a abolição, visto que seu filho Gaspar Gomes foi batizado em 1892. Dos filhos de Juliana, destacam-se, na memória do Limoeiro, Gaspar Gomes, nascido em 1886, que posteriormente se casou com Maria Carolina, que pertencia à família dos Benjamins. ${ }^{19}$

18 Nesse período, a localidade estava atrelada ao município de Nossa Senhora da Conceição do Arroio.

19 A família dos Benjamins é outro ramo familiar muito rememorado no Limoeiro, sua origem nominal deriva de Benjamim Antônio de Oliveira. Pelas memórias da comunidade, sabe-se que Benjamim era um escravo que não tinha nascido em Palmares, mas em um lugar próximo, talvez Passinhos ou Santo Antônio da Patrulha. Benjamim casou-se com Maria Antônia, filha de Perpétua e Manoel Jorge, casal que herdou terras dos Azevedo e Souza, uma importante família terratenente da localidade. Benjamim e Mônica tiveram oito filhos, dos quais pelo menos três se casaram com descendentes dos libertos legatários de Vicente José Gomes. 
Quadro 2: Batizados dos filhos de Juliana Anastácia Gomes.

\begin{tabular}{|c|c|c|}
\hline Filho & Data de nascimento & Data de batizado \\
\hline Vicente Gomes & $15 / 7 / 1879$ & $4 / 7 / 1880$ \\
\hline Alziro Gomes & $11 / 6 / 1882$ & $20 / 1 / 1883$ \\
\hline Gaspar Gomes & $19 / 11 / 1886$ & $18 / 2 / 1892$ \\
\hline
\end{tabular}

Fonte: Caderno Provisório Suplementar n. 11, Batismos de Conceição do Arroio (1877-1880). Livro n. 12 de batismos livres (1880-1884).

Percebe-se que os três filhos da legatária Juliana Anastácia Gomes nasceram ainda no período da escravidão e foram registrados como libertos, já que sua mãe era alforriada. Além disso, as crianças nasceram após a Lei do Ventre Livre, de 28 de setembro de 1871. Se Juliana ainda fosse escravizada, seus meninos poderiam ter seguido outro rumo. A lei declarava livres os filhos de mulheres escravizadas nascidos a partir daquela data; contudo, os "filhos menores" deveriam ficar sob a autoridade dos senhores de suas mães até a idade de oito anos completos, quando ou o senhor recebia uma indenização do Estado ou utilizava os serviços do menor até a idade de 21 anos completos. Desse modo, um filho de uma escravizada nascido em 1871, após a vigência da Lei do Ventre Livre, poderia ser considerado livre após 21 anos, ou seja, no ano de 1892, quatro anos após a abolição. Nota-se que a Lei do Ventre Livre foi uma tentativa de adiar o fim da escravidão. A lei de 1871 legalizou o direito costumeiro de escravizados e de escravizadas de conquistar a carta de liberdade, pois foi permitido que os escravizados e escravizadas formassem um pecúlio originário de doações, legados e heranças e ainda das economias adquiridas com seu trabalho e economia, desde que com anuência de seu senhor. Além disso, a lei colocou limites à autoridade senhorial, pois as relações até então tratadas no âmbito privado passaram a ter a intervenção estatal. Conforme argumenta Chalhoub, ao analisar as experiências no Rio de Janeiro, a lei foi "de certa forma" uma conquista dos escravizados e teve consequências importantes no processo de abolição. A lei garantia que, caso as negociações pela liberdade falhassem com os senhores, os escravizados poderiam acionar o Estado, apresentar o pecúlio e esperar o resultado do arbitramento.

Conquistas de liberdade, como a da família de Juliana, representaram a permanência dos laços de parentescos possivelmente sem a interferência do Estado e dos antigos senhores. Ser liberta durante a escravidão fez com que as leis que foram aprovadas durante o processo de desintegração da escravidão não interferissem diretamente na vida de mulheres como Juliana. Digo diretamente, pois sabe-se que o Litoral Negro apresentou inúmeras redes e Juliana poderia ter parentes e amigos ainda no cativeiro, inclusive sua mãe Anastácia. 
O censo populacional de 1872, realizado no Brasil, traz os dados da paróquia de Nossa Senhora da Conceição do Arroio e permite identificar o perfil populacional do período que é próximo às experiências de liberdade da família de Anastácia Gomes.

Quadro 3: Censo populacional de 1872, da paróquia de Nossa Senhora da Conceição do Arroio.

\begin{tabular}{|c|c|c|c|c|}
\hline \multirow{3}{*}{ Cor } & \multicolumn{4}{|c|}{ Condição social e sexo } \\
\hline & \multicolumn{2}{|c|}{ Livre } & \multicolumn{2}{|c|}{ Escravizado } \\
\hline & Homem & Mulher & Homem & Mulher \\
\hline Branca & 2.040 & 2.140 & - & - \\
\hline Parda & 241 & 205 & 239 & 173 \\
\hline Preta & 193 & 163 & 395 & 264 \\
\hline Cabloca & 23 & 11 & - & - \\
\hline
\end{tabular}

Fonte: Recenseamento Geral do Brasil em 1872. Rio Grande do Sul. Disponível em: https:// biblioteca.ibge.gov.br/visualizacao/livros/liv25477_v11_rs.pdf. Acesso em: 21 jun. 2018.

Pelos dados censitários de 1872, percebe-se que em Nossa Senhora da Conceição do Arroio, atual Osório (incluía a localidade atual de Palmares do Sul), havia uma população total de 6.087 habitantes, sendo 5.016 livres e 1.071 escravizados. A população escravizada estava dividida em 634 homens e 437 mulheres. Cabe pontuar que entre os habitantes livres estavam inclusos aqueles que conquistaram a liberdade. Desse modo, podemos observar 446 pardos e 356 pretos. É nesse contexto que a alforria dos escravizados de Vicente e de Eufrázia foi registrada, nos anos de 1870 e 1871. Possivelmente, os libertos daquele casal estejam inclusos entre os habitantes livres registrados no censo de 1872 . Nesses dados também deveria estar inserida a família de Anastácia Gomes.

Notamos ainda que, em 1872, havia 1.071 homens e mulheres à espera da liberdade. A lei de 1871 poderia ter acelerado a entrada pela estreita porta da liberdade, pois a carta de alforria deixou de ser algo costumeiro negociado partir da relação senhor-escravizado e acionou o Estado para as negociações. Weimer ${ }^{20}$ investigou 246 cartas de alforria registradas em Conceição do Arroio, entre 1859 e 1888, e as dividiu em três períodos, 1859-1871; 1871-1880; 1880-1888. Observando a média anual dos registros, destacou que, no primeiro período, houve 87 manumissões; no segundo, 25 cartas, e no terceiro, 134 registros de liberdade. Desse modo, temos o período logo após a Lei do Ventre Livre (1871-1880) com um

20 WEIMER, Rodrigo de Azevedo. A gente da Felisberta. Consciência histórica, história e memória de uma família negra no litoral sul-rio-grandense no pós-emancipação. (c.1847 ao tempo presente) Tese (Doutorado em História) - Universidade Federal Fluminense, Rio de Janeiro, 2013. 
decréscimo quando comparado ao primeiro recorte temporal. O maior número de conquistas de liberdade ocorreu nos anos de 1880, acompanhando o restante da província. Quando cruzamos os dados do censo de 1872, o qual informa que havia, em Conceição do Arroio, 1.071 escravizados com as cartas de alforria (que apontam para aproximadamente 150 libertos), então podemos considerar que muitos homens e mulheres tiveram que esperar a abolição para se livrar do cativeiro.

Retornando à matriarca Chica Brincuda, nossa personagem possivelmente fosse Francisca Joana Gomes, pois os quilombolas do Limoeiro apontaram o nome de "Jove" como uma filha da escravizada. Tudo indica que Jove era o apelido de Jovelina Gomes, conforme gráfico genealógico a seguir.

Gráfico genealógico 2: Família de Chica Brincuda.

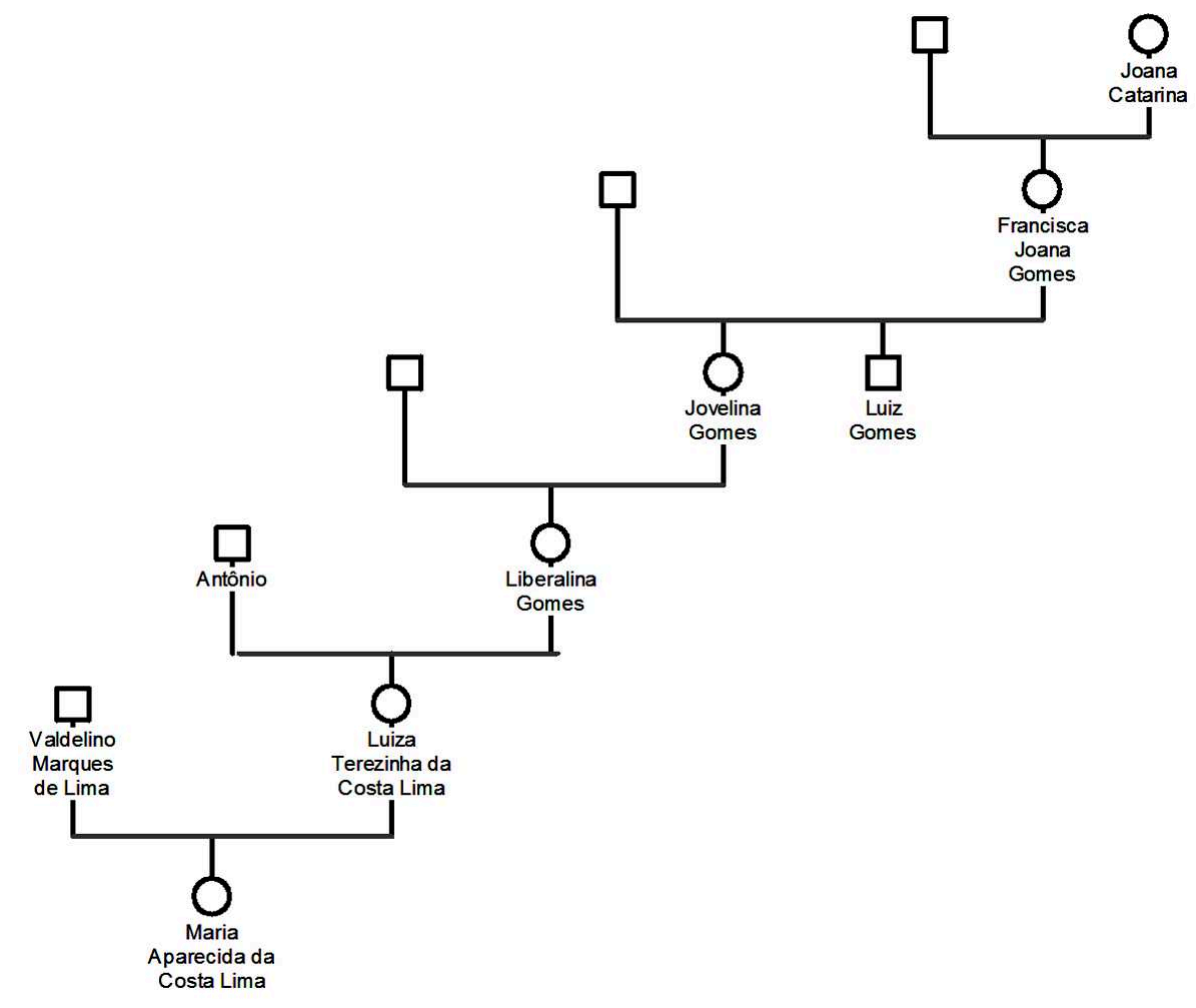

Pela árvore genealógica realizada a partir da memória dos quilombolas do Limoeiro e de registros de batismos, nota-se que há uma grande presença de mulheres nas gerações. Além da matriarca Chica Brincuda (Francisca Joana Gomes), aparecem sua filha Jovelina Gomes, sua neta Liberalina Gomes, a bisneta Luiza Terezinha e a tataraneta Maria Aparecida. Com exceção de Liberalina e de Luiza, as demais mulheres não estão acompanhadas pelos seus companheiros, o que aponta para mulheres que sustentavam sua família. Isso talvez indique a ligação de Chica Brincuda com Anastácia e Juliana, pois em uma sociedade patriarcal, em que as 
mulheres negras são preteridas e sofrem o preconceito racial e social, a tessitura de redes de solidariedade é fundamental para a manutenção de suas famílias.

O patriarcado assumiu o modelo tradicional das famílias brasileiras, porém, desde a escravidão, muitas famílias negras foram moldadas a partir da matrilinearidade. A família de Chica Brincuda forja-se na contramão do patriarcado, sustentando-se a partir de protagonistas que marcaram as vivências da região e que são rememoradas em pleno século XXI pelos descendentes quilombolas.

Cabe lembrar que Juliana é rememorada como parteira da região, quiçá foi a ex-escravizada que realizou os dois partos de Francisca Joana Gomes e isso aproximou-as ainda mais. Logicamente, são apenas ilações, mas sabemos o quanto o litoral foi carente de pessoas que fizessem partos ou benzeduras. Witter, ao investigar as práticas de cura no Sul do Brasil, no século XIX, informa que as mulheres ocupavam um lugar especial no que tange às doenças, pois eram as primeiras curadoras de quase todas as moléstias. Havia, desse modo, o estabelecimento de redes de solidariedade e de favores entre elas. Eram as mulheres que faziam os partos, auxiliavam no trato de doenças e ainda banhavam os mortos. Desse modo, mantinham uma ligação profunda com os elementos que constituíam a vida e a morte. ${ }^{21}$ Witter assinala que as parteiras tinham função de destaque nas comunidades em que atuavam. A autora argumenta que era comum as parteiras que desempenhavam suas atividades na zona rural, afastadas do centro, mudarem-se para a casa da gestante, algumas semanas antes da data prevista para o nascimento. E, após o nascimento, ainda ficavam alguns dias cuidando do bebê e da mãe. Além disso, havia uma forte ligação entre as parteiras e as parturientes. Cabe aqui pensar que Jovelina e Luiz podem ter nascido pelas mãos de Juliana, na década de 1880.

Quadro 4: Batizados dos filhos de Francisca Joana Gomes.

\begin{tabular}{|c|c|c|}
\hline Filhos & Data de nascimento & Data de batizado \\
\hline Jovelina $^{1}$ & $20 / 10 / 1883$ & $18 / 9 / 1886$ \\
\hline Luiz $^{2}$ & $6 / 8 / 1886$ & $18 / 9 / 1886$ \\
\hline
\end{tabular}

De acordo com os registros de batizados, Jovelina nasceu no ano de 1883 e Luiz, três anos após, embora tenham recebido os santos óleos em 1886. Em ambos registros constam apenas os dados da filiação materna e o nome da avó, Joana Catarina Gomes. Os padrinhos de Jovelina foram Idalino Francisco da Silveira e Marcelina Luiza da Conceição; desconhecemos esses nomes. O menino Luiz teve

21 WITTER, Nikelen Acosta. Dizem que foi feitiço: as práticas da cura no sul do Brasil (1845 a 1880). Porto Alegre: EDIPUCRS, 2001. 
como padrinhos Narcizo José Gomes e Laurinda Narciza Gomes. No caso desses padrinhos, temos alguns apontamentos, afinal o sobrenome "Gomes" pode ser um indicativo de parentescos ou ainda de experiências comuns no cativeiro da Fazenda do Ipê. Entre os libertos de Vicente e Eufrázia, listados anteriormente, temos a escravizada Narciza, que pode ser parente dos padrinhos de Luiz, especialmente porque notamos que, nas práticas de nominação, há escravizados que adotam sobrenomes e nomes senhoriais e nomes de seus ancestrais.

Chica Brincuda é relembrada como uma mulher ex-escravizada que era muito rebelde, matriarca da família; aliás, percebe-se como as mulheres destacaram-se nesse grupo familiar. A quilombola do Limoeiro, Luísa Marques, relembra sobre o apelido de Chica Brincuda, além de reforçar que a nossa personagem era escravizada e legatária de terras na região.

losvaldyr Carvalho Bittencourt Junior; ${ }^{22}$ A senhora sabe me contar como era a Chica Brincuda?

Luísa Marques: Era do Limoeiro, e a Jove, que era filha da Chica. Chamavam de Chica Brincuda porque ela tinha um orelhão, que nem um brinco. Daí chamavam de Chica Brincuda. Mas tem gente dela aí, ali a Catarina.

losvaldyr Carvalho Bittencourt Junior: E essas terras, ela ganhou?

Luísa Marques: Ganhou dos escravos, ela era escrava. ${ }^{23}$

Davis $^{24}$ comenta que, na França, durante o século XVI, mulheres de vida pública, que não eram prostitutas, mas transitavam juntamente com aquelas e agiam no espaço público a trabalho, costumavam receber apelidos, parece que isso ocorreu com Chica Brincuda.

Dona Maria do Carmo é uma mulher branca que foi criada por pais negros, além de ser viúva de um quilombola do Limoeiro. Ela traz muitas memórias do seu falecido marido e nos conta um pouco sobre Chica Brincuda.

Claudia Daiane: O que mais a senhora estava falando da Chica Brincuda?

Maria do Carmo: Que ela foi a última a ficar nessas terras de escravo, onde apareceu um homem, ele deu o nome, mas eu não sei, eu não lembro o nome, que este homem apareceu aí, começou de namoro com ele, parece que uma coisa assim. Depois ele agarrou e se "adonou" dessas terras mais tarde, tirando dela e comprando uma terra para este canto aí, para ela vir morar aqui, que ela estava muito para lá dos escravos restantes. Ela saiu e fez uma casa mais para cá, que era melhor para ela, eu não sei como foi (...)

22 Antropólogo que atuou no Relatório socio-histórico e antropológico da comunidade remanescente quilombola do Limoeiro.

23 Entrevista realizada com dona Maria do Carmo, na comunidade do Limoeiro, em 2008.

24 DAVIS, Natalie Zemon. Mulheres urbanas e mudança religiosa: In: DAVIS, Natalie Zemon. Culturas do povo: sociedade e cultura no início da França moderna. Rio de Janeiro: Paz e Terra, 1990. p. 63-86. 
Claudia Daiane Garcia Molet ${ }^{25}$ : Qual o nome dos filhos dela?

Maria do Carmo: Eu ouvi falar em Jovelina e esse outro... Jovelina eu sei que era filha dela (...) de onde vem... De onde era essa família da Catarina daqui que é bisneta dessa gente, essa Catarina aqui do João.

Claudia Daiane Garcia Molet: Eu não falei com a Catarina.

Maria do Carmo: Não falou? Foram os outros, ${ }^{26}$ eu acho que aqueles outros já tiveram ali.

Claudia Daiane Garcia Molet: Já passaram ali?

Maria do Carmo: Já passaram. Andavam atrás da foto com a Luísa e não sei o que, andavam procurando. A mãe dele era a falecida Libera, eu acho que essa Libera era filha da Jovelina. Alfredino, o filho dessa. Não sei se era filho da Jovelina ou da Chica Brincuda, que chamam. A Jovelina eu cheguei a conhecer, tinha uma papada grande assim, mas essa outra não, o meu marido chegou a conhecer.

Claudia Daiane Garcia Molet: A Chica Brincuda ganhou terras, seria isso?

Maria do Carmo: Ela era restante, que ainda morava em cima dessas terras por esses lados para dentro. Não dentro destas terras aqui, além...

O relato de dona Maria do Carmo ratifica que Chica Brincuda foi "a última a ficar nessas terras de escravos", o que pode indicar que a escravizada parece ser a última a ser liberta, ou ainda a derradeira herdeira a ficar no imóvel legado; mas cabe pontuar que encontramos outros descendentes dos demais herdeiros libertos, como no caso do litígio das terras na década de 1960 envolvendo os descendentes dos libertos de Vicente José Gomes e a vizinhança. Logo que cheguei à comunidade remanescente quilombola do Limoeiro, em 2008, os quilombolas comentaram sobre o grupo familiar dos "Albinos", ressaltando que os mesmos tiveram sérios problemas com suas terras, restando poucos remanescentes na atualidade, pois haviam perdido e/ou vendido seus imóveis. Os "Albinos" também eram conhecidos como os "negros do Ipê", termo que está relacionado com a antiga Fazenda do Ipê, cujos proprietários eram Vicente José Gomes e Gertrudes Eufrázia Lopes, conforme analisado anteriormente. Na década de 1870, esse casal libertou 16 escravizados e entre eles estava Albino, que na época da conquista da manumissão estava com 25 anos de idade. A herança conquistada no século XIX foi acionada na década de 1960, quando os herdeiros de Albino entraram com uma ação judicial denunciando as recorrentes invasões em suas propriedades. Após intensas disputas, parece que as terras dos Albinos foram em parte ocupadas por uma reforma agrária realizada

25 Assistente de História no Relatório socio-histórico e antropológico da comunidade remanescente quilombola do Limoeiro.

26 Dona Maria do Carmo refere-se aos demais membros da pesquisa do relatório socio-histórico e antropológico do Limoeiro. 
por Leonel Brizola, na chamada Fazenda do Pangaré; este, por sua vez, alegava que havia adquirido as terras de outro vizinho das famílias negras.

O plano de reforma agrária, na Fazenda do Pangaré, previa a distribuição de terras e a assistência técnica social aos trabalhadores assentados. 1.200 hectares foram distribuídos a camponeses onde seria cultivado arroz a partir de uma cooperativa. O projeto da reforma agrária assentou aproximadamente 30 famílias, tanto da região como de outras localidades, como Serra e Planalto. O projeto vigorou de 1961 a 1964. As famílias foram abandonando as terras, pois ficaram sem apoio; as chácaras foram vendidas para outros proprietários. ${ }^{27}$ Entretanto, a reforma agrária foi assentada em terras da comunidade remanescente do Limoeiro.

Outro indício que Chica não teria sido a última a sair das terras é o fato de que, em 2008, ainda havia parentes de Chica Brincuda na comunidade remanescente do Limoeiro, mas não foi possível obter muitas informações sobre a escravizada. Importante mencionar que a filha de Juliana Anastácia Gomes, Maria Carolina, casouse com um membro da família dos Benjamins. No final do trecho da entrevista, dona Maria do Carmo ressalta que Chica era a última que residia nas terras "por esses lados de dentro", o que pode indicar que havia outros herdeiros em outras localidades.

Retomando a narrativa de dona Maria do Carmo, a entrevistada aponta para uma experiência amorosa de Chica Brincuda, que teria acarretado perdas das terras herdadas. O parceiro teria se "adonado" do imóvel e, em troca, comprado outro terreno. Em suas palavras, a troca teria beneficiado Chica, possivelmente porque a casa da ex-escravizada teria ficado mais próxima dos demais camponeses negros. Porém, destaco que o interesse nas terras de Chica, por parte de seu companheiro, indica que o imóvel poderia ter valor maior do que aquele terreno com casa do qual Chica ficou beneficiária.

Dona Maria do Carmo aponta alguns membros da família de Chica Brincuda. Jovelina seria mãe de Libera, ou Liberalina, como aparece em outros depoimentos. Além dessas duas, ainda aparece o nome de Alfredino, que a entrevistada não lembra o parentesco, se era filho de Jovelina ou de Chica Brincuda. Chica Brincuda possuía uma família em que as mulheres se destacam nas memórias da comunidade do Limoeiro. Até o presente momento, conhecemos, além de Chica, Anastácia, Juliana, Jovelina e Liberalina. Dentre estas, Chica Brincuda destaca-se como a matriarca da família, sendo reconhecida como herdeira de terras, a última das escravas a andar pelas terras de Palmares e ainda como uma escravizada muito rebelde.

27 Relatório socio-histórico e antropológico da comunidade remanescente quilombola do Limoeiro, 2008. 
O quilombola do Limoeiro, seu José Carlos Bellos de Lima, ao mencionar Chica Brincuda, aponta para a existência de parentescos no Limoeiro com as comunidades quilombolas de Viamão.

José Carlos: Uma coisa curiosa que o Cléber descobriu é que ali no... para cá de Viamão, na Lomba, tem uns quilombos ali, não é? E tem família de origem dessa Chica Brincuda. Esse Vicente Gomes tinha esta fazenda aqui e tinha um irmão dele que tinha uma fazenda ali entre Santo Antônio, por ali assim. Então eles faziam ali e iam ficando escravo desta fazenda, para outra fazenda do irmão de lá. Então por isso que tem essa descendência dessa Chica Brincuda para lá. Então é uma coisa boa da gente descobrir.

Catarina: Mas um parente do tio Gaspar, irmão da nossa avó, foi morar ali para a Lomba.

José Carlos: Pois é onde tem...

Catarina: Foram dois, um chamava Gaspar e outro José, eu acho que a tia Milca é dessa gente.

Claudia Daiane: E o Gaspar é irmão de quem?

José Carlos: Irmão da nossa avó.

Claudia Daiane: Qual avó?

José Carlos: Maria Carolina.

Claudia Daiane. Ok.

José Carlos: Juliana... era irmão da Juliana. Irmão não, filho. A Juliana era parteira.

Claudia Daiane: Parteira! E o Gaspar, irmão da Maria Carolina!

José Carlos: $E$ da Juliana também. E esses outros dois que dizem que foram morar lá para a Lomba, também eram filhos da Juliana.

Claudia Daiane: Como se chamavam? Uma era Gaspar...

José Carlos: José e o outro Vicente.

Claudia Daiane: José e Vicente. ${ }^{28}$

Seu José destaca que Vicente José Gomes, proprietário de terras em Palmares, possuía um irmão em Santo Antônio da Patrulha e por isso havia a circulação de escravizados entre as propriedades da família. Talvez os serviços executados por homens fossem mais requisitados e por isso as mulheres escravizadas circulavam mais pela região, sendo inclusive chefes de família. Vicente se deslocou de Santo Antônio da Patrulha para Palmares, na segunda metade do século XIX, onde adquiriu terras da família Azevedo e Souza. Além dessa circulação de escravizados, que justificaria os parentescos entre as comunidades quilombolas, José pontua a ida de Gaspar e de José, ambos filhos de Juliana Anastácia Gomes, para a região de Viamão.

Silveira, ${ }^{29}$ na dissertação de mestrado em Desenvolvimento Rural, analisa as relações de reciprocidades entre duas comunidades remanescentes quilombolas

28 Entrevista realizada com seu José Carlos Bellos de Lima e sua esposa Catarina Lima, na comunidade do Limoeiro, em 2008.

29 SILVEIRA, Luciana Conceição Lemos da. Relações de reciprocidade quilombola: Peixoto dos Botinhas e Cantão das Lombas - município de Viamão (RS). 2010. Dissertação (Mestrado em Desenvolvimento Rural) - Universidade Federal do Rio Grande do Sul, 2010. 
localizadas em Viamão/RS: Peixoto dos Botinhas e Cantão das Lombas. A autora aponta uma família que possui membros em Cantão das Lombas e no Limoeiro, conforme seu José Carlos mencionou na entrevista. Segundo Silveira, um de seus entrevistados, seu Arno Gomes, conhecido pelo apelido de Cai-Cai, quilombola do Cantão das Lombas, que possui um primo em Peixoto dos Botinhas, tem uma irmã no Limoeiro, dona Nilza Gomes. O sobrenome Gomes aparece nos quilombos de Viamão e há parentescos conforme mencionamos, embora não se identificou a ligação com Chica Brincuda, mas sim de seus descendentes, pois Nilza Gomes, citada por Silveira, é neta de Chica Brincuda.

Chica Brincuda está presente na memória da comunidade quilombola remanescente. Na época do relatório socio-histórico e antropológico, os entrevistados apontavam para o quilombola seu Ico como o detentor das histórias desta escravizada. Infelizmente, seu Ico estava doente e veio a falecer logo no começo da pesquisa para a realização do relatório, em 2008. Porém, foi possível coletar algumas informações sobre essa mulher negra. Chica não está no rol dos escravizados libertos e legatários de Vicente José Gomes e Gertrudes Eufrázia Lopes, mas cabe pontuar que essa mulher poderia ser escravizada de algum parente de Vicente. $\mathrm{Na}$ época dos registros de alforrias do casal Vicente e Gertrudes, na década de 1870, analisados anteriormente, há a informação de que um dos escravizados, Francisco, filho de Idalina, ficaria em propriedade do sobrinho do casal, Jerônimo José Lopes. Desse modo, Chica poderia trabalhar em outras fazendas da família Gomes.

Chica Brincuda, portanto, foi uma mulher negra, escravizada no litoral do Rio Grande do Sul, que conquistou a liberdade, teceu importantes redes de parentescose solidariedades com outras mulheres negras da região, foi matriarca de sua família dos Gomes e é rememorada pelos remanescentes quilombolas do Limoeiro. Juntamente com outras mulheres escravizadas que se destacaram na herança, ficando com alguns pertences materiais e inclusive com escravizados de seus antigos senhores. Mães que viram seus filhos nascerem durante a escravidão, mas que conquistaram a porta da liberdade e puderam cultivar sua alimentação no pequeno pedaço de terra legado. Chefes de família rememoradas até a atualidade por seus ancestrais, como Chica Brincuda, Juliana e Anastácia.

Recebido em 22/08/2019 Aprovado em 16/10/201 